\title{
Diet, exercise and mental-wellbeing of healthcare professionals in Pakistan
}

Waqas Ahmad, Frances Taggart, Muhammad Shoaib Shafique, Yumna Muzafar, Shehnam Abidi, Noor Ghani, Zahra Malik, Tehmina Zahid, Ahmed Waqas, Naila Ghaffar

Background: "Health is wealth" is a time tested adage. Health becomes more relevant when it comes to professionals whose job is to provide people with services that maintain an optimum state of mental, physical and social well-being. Healthcare professionals (HCP) differ from general population in regards to the nature of their work, stress, burnout etc. which begs the need to have a robust state of health for the ones who provide it to others. We initiated this study to see if healthcare professionals "practice what they preach others" Methods: We employed a cross-sectional study design with convenience-sampling technique. Questionnaires were administered directly to the three groups of healthcare professionals (Doctors, Dentists and Nurses) across the province Punjab after their consent. 1319 healthcare professionals took part in the study (response rate of 87.35). Warwick Edinburg Mental Wellbeing Scale (WEMWBS) was used to assess mental wellbeing. USDA Dietary Guidelines-2010 were employed to quantify diet. American Heart Association (AHA) guidelines were employed for the analysis of exercise. Results: A total of 1190 healthcare professionals formed the final sample with doctors and nurses forming the major proportion. Out of 1190 participants only one healthcare professional was found to eat according to USDA Dietary Guidelines; others ate more of protein group and less of fruits, dairy and vegetable groups. $76 \%$ did not perform any exercise. $71.5 \%$ worked $>48$ hours/week. More than $50 \%$ of healthcare professionals were sleeping $<7$ hours/day. WEMWBS score of the entire sample was $47.97 \pm 9.53$ S.D. Conclusion: Our findings suggest that healthcare professionals do not practice what they preach. Their mental wellbeing, diet and exercise habits are not up to the mark and should be improved to foster the whole healthcare system for individual and community benefits. 
1 Diet, Exercise and Mental-Wellbeing of Healthcare Professionals of Pakistan.

3 Authors: Waqas Ahmad ${ }^{1 *}$, Frances Taggart ${ }^{2}$, Muhammad Shoaib Shafique ${ }^{1}$, Yumna

4 Muzafar ${ }^{1}$, Shehnam Abidi ${ }^{1}$, Noor Ghani ${ }^{1}$, Zahra Malik ${ }^{1}$, Tehmina Zahid ${ }^{1}$, Ahmed

5 Waqas $^{1}$, Naila Ghaffar ${ }^{1}$.

$7 \quad{ }^{1} \mathrm{CMH}$ Lahore Medical College and Institute of Dentistry, Shami Road, Lahore

8 Cantt, Pakistan.

$9 \quad{ }^{2}$ Statistics and Epidemiology Unit, Division of Health Sciences, University of

10 Warwick Medical School, Coventry, UK.

*Corresponding Author

E-mail: waqas_lalamusa@yahoo.com (WA) 
Abstract:

21 Background: "Health is wealth" is a time tested adage. Health becomes more relevant when it comes to professionals whose job is to provide people with services that maintain an optimum state of mental, physical and social well-being. Healthcare professionals (HCP) differ from general population in regards to the nature of their work, stress, burnout etc. which begs the need to have a robust state of health for the ones who provide it to others. We initiated this study to see if healthcare professionals "practice what they preach others"

27 Methods: We employed a cross-sectional study design with convenience-sampling technique. Questionnaires were administered directly to the three groups of healthcare professionals (Doctors, Dentists and Nurses) across the province Punjab after their consent. 1319 healthcare professionals took part in the study (response rate of 87·35). Warwick Edinburg Mental Wellbeing Scale (WEMWBS) was used to assess mental wellbeing. USDA Dietary Guidelines-2010 were employed to quantify diet. American Heart Association (AHA)

33 guidelines were employed for the analysis of exercise.

34 Results: A total of 1190 healthcare professionals formed the final sample with doctors and nurses forming the major proportion. Out of 1190 participants only one healthcare professional 
was found to eat according to USDA Dietary Guidelines; others ate more of protein group and less of fruits, dairy and vegetable groups. $76 \%$ did not perform any exercise. $71.5 \%$ worked $>48$ hours/week. More than $50 \%$ of healthcare professionals were sleeping $<7$ hours/day. WEMWBS score of the entire sample was $47.97 \pm 9.53$ S.D.

Conclusion: Our findings suggest that healthcare professionals do not practice what they preach. Their mental wellbeing, diet and exercise habits are not up to the mark and should be improved to foster the whole healthcare system for individual and community benefits.

\section{Introduction:}

Health is defined by W.H.O. as "a state of complete physical, mental and social well-being and not merely the absence of disease or infirmity" (W.H.O, 1948). Healthy lifestyle has many advantages: a balanced diet lowers the risk of many cardiovascular diseases (Gambera, Schneeman \& Davis, 1995); regular exercise helps reduce anxiety and depression, lowers cholesterol level and boosts the immune system(American Heart Association, 2013); a good mental wellbeing helps cope with daily stress and work productively for individual and community benefit (Huppert, 2009), avoidance of first and second hand smoke protects against many respiratory and cardiovascular diseases (Ockene \& Miller, 1997).

In recent years mental wellbeing has come to the limelight due to its role in coping and protection against different mental illnesses (Huppert, 2009). It equips an individual with resilience, better physical health, financial and personal security, better relationships with friends and family and improves his quality of life (Deacon et al., 2009). Mental wellbeing 
becomes more important when it comes to healthcare professionals who deal with life and death, work long hours, get little time to spend with family and are exposed to violence, insecurity and illegitimate pressures (Shiwani, 2009). They are more susceptible to stress and its negative consequences than general population (Willcock et al., 2004), (Schattner, Davidson \& Serry, 2004).

Doctors and other healthcare professionals (nurses, dentists) work in harmony to provide optimum care to patients. They do not just work for a disease free community but one with a healthy lifestyle. They provide advice on how to eat right, how to live long, how to be mentally strong to deal with everyday challenges but the questions arise: do they act on their own advice, do they eat right, sleep well, exercise. Are they in a state of good mental well-being to deal with everyday challenges?

Research has shown that doctors who have a healthy lifestyle are more likely to talk to their patients about it (Oberg \& Frank, 2009) and patients are more likely to take impression from such doctors (Frank, Breyan \& Elon, 2000). Healthy healthcare professionals not only perform well but also foster the healthcare system which leads to the ultimate goal of medical practice; better patient care. American (Frank, 2004) and Canadian(Frank \& Segura, 2009) doctors are healthier than general population but such studies are much more scarce in Asia as compared to the rest pf world. We initiated this study to see if healthcare professionals of the sixth most populous country in the world "practice what they preach" by chiefly examining their diet, exercise and mental wellbeing along with other aspects which affect their lives e.g. sleep, BMI etc. 
Methodology:

78

79

80

81

82

83

84

85

86

87

88

89

90

91

92

93

94

95

96

97

\section{Subject group and Sampling:}

Descriptive, cross-sectional study design and convenience-sampling technique (non-probability sampling) was employed. A total of 1510 healthcare professionals were approached out of which 1319 took part in the study, response rate of $87 \cdot 35 \%$. Sample size calculation is based on anticipated effect sizes, however, no apriori power estimates were available for multiple regression analysis employed in present study. The authors followed the sample size recommendations made by Vanvoorhis and Morgan (VanVoorhis \& Morgan, 2007). According to Vanvoorhis and Morgan, regression equations with six or more predictors should have a minimum of 10 participants per predictor variable. Three groups of healthcare professionals were included in the study: doctors, nurses and dentists. 129 responses were discarded due to missing dietary intake; essential demographics like age, gender, profession etc. all together and more than 3 missing responses in Warwick Edinburg Mental Wellbeing Scale (WEMWBS) thus making the final sample $\mathrm{N}=1190$. Junior doctors were defined as those doctors who were $\leq 30$ years old and in their early years of training while senior doctors were defined as all those doctors who were $>30$ years of age. On the basis of monthly income, following groups were created Low Income ( $\leq$ PKR. 8, 500), Lower-Middle Income ( $\geq$ PKR. 8, 501 and $\leq$ PKR. 33, 000), Upper-Middle Income ( $\geq$ PKR. 33, 001 and $\leq$ PKR.102, 000) High-Income (> PKR.102, 001).Occupational stressors are defined as all those stresses which are chiefly present in a work place environment (Hospital, clinics etc.). Following stressors were asked about Long Working Hours, Patient Overload, Uncertain Future, Insufficient Opportunities to prosper; illegitimate 
98

99

100

101

102

103

104

105

political, administrative etc. pressure (Kazmi, Amjad \& Khan, 2008) . Questionnaires were administered directly to the subjects after their consent. Data collection was done between March and July 2013 from hospitals and private clinics in 8 major cities of the province Punjab.

\section{Mental Wellbeing Scale:}

Warwick Edinburg Mental Wellbeing Scale (WEMWBS) was used to assess mental wellbeing which is reliable and validated scale (Clarke et al., 2011) which is well received in English understanding Pakistani population (Taggart et al., 2013). WEMWBS showed good psychometric properties for Pakistani population. WEMWBS was cross culturally validated for Pakistani population. It exhibited excellent psychometric properties; good face validity, a unidimensional construct, a high internal consistency $(0.89)$ and test-retest reliability and easy readability of WEMBS among Pakistani HCPs. Both principal component analysis and principle axis factoring demonstrated similar factor structure of WEMWBS (Waqas et al. 2015). It contains 14-positive items covering both eudaimonic and hedonic aspects of mental wellbeing and is scored on a 1 to 5 Likert scale to assess the frequency of occurrence of each item with 1 corresponding to "None of the time" and 5 corresponding to "All of the time" in an ordinal fashion. Total score ranges from 14 to 70 with higher scores representing higher levels of mental wellbeing.

\section{Dietary Patterns:}

Intake of 5 major food groups (Table S1) was asked over past 7 days and reported as 1 day average to compare with USDA Dietary Guidelines-2010. Food items were analysed using a standardised conversion scale (Table S1) to convert the amount of food eaten into servings. 


\section{Exercise:}

120 Exercise was recorded by a 7-day recall and presented in minutes. Exercise was divided into

121 moderate, vigorous and muscle strengthening activities. American Heart Association guidelines

122 for exercise were used (150mins/week of moderate activity or $75 \mathrm{mins} /$ week of vigorous activity

123 or a combination of both) (Haskell et al., 2007). For the simplicity of analysis and interpretation

124 vigorous activity minutes were multiplied by 2 . This helped in making the cut-offs for

125 combination of the two activities i.e. individuals doing both moderate and vigorous activities.

126 Recommended activity was set at when collective sum for two activities was equal to or more

127 than 150 minutes/week.

\section{Statistical Analysis:}

SPSS Inc., (Chicago, Illinois, USA) version 21 software was used for analysis Descriptive statistics are shown for gender, medical profession etc. One way ANOVA and Independent-sample t-test were used for the comparison of means. Multiple Linear Regression analysis was run to analyze association of scores on WEMWBS (dependent variable) with demographic characteristics of respondents, age, income, profession, psychosocial stressors and dietary habits entered as predictor variables. Histogram and P-P plots were visualized to assess the assumption of normality of data. Durbin Watson test, case wise diagnostics and values of variance inflation factor (VIF) and tolerance (TOL) were run to ensure all assumptions of multiple regression analysis were met. Variables with more than two categories such as body mass index (BMI), profession of healthcare professionals and dietary habits were coded as dummy variables for multiple regression analysis. P values $<.05$ were considered statistically significant. 
Ethics Statement:

141 CMH Lahore Medical and Dental College Ethical Review Committee approved the study

142 questionnaire.

\section{Results:}

144 Large proportion of the final sample was occupied by Doctors, as shown in Table 1, with $58.7 \%$

145 females and 41.3\% males. Mean working hours/week for Doctors=64.98 $\pm 16 \cdot 86$ S.D with junior

146 doctors working an average of 7 hours/week more than senior doctors (Table 2), Nurses=52.73

$147 \pm 17 \cdot 29$ S.D, Dentist=47.32 \pm 14.02 S.D. When asked about the comfortable working hours,

148 professionals from all groups demanded reduction in current working hours by $20,12,11$ hours

149 respectively $(p<0 \cdot 05) .50 \%$ of the participants were sleeping $<7$ hours/day with doctors leading

150 the list (74.5\%). Doctors (66.9\%) also lead the list of healthcare professionals getting

151 recommended sleep (7-8 hours)(Foley et al., 2004). The most common chronic disease was

152 visual defects (22.6\%) like Myopia or Hyperopia next to back problems (9.7\%) (Table 3). 10.4\%

153 of the participants were identified as smokers, smoking a median of 8 cigarettes/day. Only

$15434.5 \%$ were spending as much time with their family as much they like to. $70.3 \%$ of the

155 participants $(F>M)$ perceived themselves to be under occupational stress (Table 4). A significant

156 majority (71.6\%) said that they would not change their profession if they had the option.

\section{Junior Vs Senior Doctor:}

158 Junior doctors, as opposed to senior doctors, had lower WEMWBS scores, lower breakfast

159 frequency, lower vegetable intake, high fruit intake, higher working hours and a relatively

160 potent desire to change their profession (Table 2). 


\section{Diet:}

162 Out of 1190 participants, only one healthcare professional was taking the recommended

163 servings. Protein over-eating was consistently high in all the 3 groups of healthcare

164 professionals while the most neglected groups were Vegetables, Dairy and then Fruits (Table 3).

165 Grains group had most professionals (60.6\%) taking the recommended servings. $49.6 \%$ of the

166 participants ate breakfast daily. $71.9 \%$ of the participants ate fast-food less than 5 times/week.

167 Most of participants (58.2\%) were at a healthy weight ( $\mathrm{F}>\mathrm{M})$; $29.5 \%$ were in pre-obesity range

$168(\mathrm{M}>\mathrm{F}) ; 7.3 \%$ were under-weight $(\mathrm{F}>\mathrm{M})$; $5 \%$ were obese $(\mathrm{M}>\mathrm{F})$. About $34.5 \%$ drank $<6$ glasses of

169 water in a single day. Tea was the most frequently consumed (83.3\%) caffeinated drink while

170 only $25.7 \%$ of the participants consumed coffee; both with a frequency of $1-2$ times a day.

\section{Exercise:}

$17276.2 \%$ healthcare professionals did not exercise at all $(\mathrm{F}>\mathrm{M})$ with doctors making the largest

173 contribution (Table 3). Out of those who did exercise, only $12.5 \%$ did recommended exercise

$174(\mathrm{M}>\mathrm{F})$ with dentists making the largest contribution. Only 3.52\% of the participants did any

175 muscle strengthening exercise.

\section{Mental Wellbeing:}

Mean WEMWBS score of the entire sample was $47.97 \pm 9.53$ S.D. Doctors scored $47.72 \pm 9.57$

S.D, Nurses $47.73 \pm 9.44$ S.D and dentists scored $49.92 \pm 9.26$ S.D. Dentists showed the highest

179 levels of metal wellbeing as compared to doctors and nurses $(p<0.05)$. Male participants scored

180 higher $(49.07 \pm 9.28$ S.D) than their female counterparts $(47.21 \pm 9.64$ S.D) $(p<0.05)$. 
181 All assumptions of multiple regression analysis were met (Table 5). Multiple regression analysis 182 revealed that mental wellbeing is positively associated with having breakfast daily, supplement

183 intake, unsaturated fatty acids often instead of very frequently, presence of hypertension,

184 working recommended and > recommended hours (7-8 hours) and comparing with low intake

185 of grains, proteins and fruits according to USDA guidelines; HCPs who reported high grain

186 intake, high protein intake and high fruit diet had higher WEMWBS scores. Whereas eating

187 restaurant made meals, high coffee and tea intake, back problems, low BMI, perception of not

188 being treated properly in the society, desire to choose a different profession, perceived

189 occupational stress, perceiving administrative and political pressure, doing no exercise

190 compared to both AHA recommended or less than AHA recommended exercise regimes and

191 low income were negatively associated with WEMWBS scores. 


\section{Discussion:}

193 Our study showed that healthcare professionals do not "practice what they preach". They

194 tend to be smokers, work excessively, have unhealthy dietary patterns and do not exercise or

195 sleep according to recommendations. Dietary pattern of healthcare professionals of Pakistan

196 are typical of ordinary citizens which is dominated by meat consumption and is low in fruits

197 and vegetables (Gallup Pakistan, 2011). About 50\% of Canadian physicians eat the

198 recommended amount of fruit and vegetables (Frank \& Segura, 2009) while only 9\% of

199 Pakistani physicians eat recommended serving of fruit and 3.8\% eat recommended servings of

200 vegetables. Despite poor dietary habits, $61.2 \%$ of Pakistani doctors $[F>M(p<0 \cdot 05)]$ have a

201 healthy weight as opposed to 54\% of Canadian doctors ( $\mathrm{F}>\mathrm{M}), 26.8 \%$ Pakistani doctors are

202 over-weight as opposed to $37 \%$ of Canadian doctors. $4.7 \%$ of Pakistani doctors are obese as

203 opposed to $8 \%$ of Canadian doctors and $7.4 \%$ of Pakistani doctors are under-weight as

204 opposed to $1 \%$ of Canadian doctors (Frank \& Segura, 2009). These findings are paradoxical if

205 we look at the dietary and exercise habits of Pakistani healthcare professionals. These findings

206 might be due to differences in total calorie intake, possibly larger portion sizes, consumption

207 of high calorie snacks such as sugary drinks, cakes and biscuits etc. between meals and also

208 alcohol may be higher in the Canadian doctors. There is also a difference in ethnicity, body fat

209 distribution for the same BMI etc. which has led to the debate about setting different BMI

210 guidelines for Asian population (WHO, 2004). More than 3/4th of healthcare professionals do

211 not exercise with less than $13 \%$ doctors getting the recommended exercise as opposed to $21 \%$

212 doctors in UK (Gupta \& Fan, 2009) while Canadian doctors exercise 20-25 minutes daily,(Frank 
213 \& Segura, 2009) less than the recommendations of American Heart Association (AHA) (Haskell

214 et al., 2007). Mental well-being scores of healthcare professionals are at an intermediate level

215 which corresponds to an intermediate state of mental wellbeing. Professionals with higher

216 incomes scored better because financial security gives you peace of mind and aids in achieving

217 good health (Marmot, 2002). Healthcare professionals who do not eat breakfast daily either

218 due to shortage of time or not being in the habit scored lower on WEMWBS which shows that

219 a lifestyle without daily breakfasts renders you less mentally resilient. Females scored lower

220 on WEMWBS than males possibly due to their susceptibility towards stress and its negative

221 consequences more than their male counterparts (American Psychological Association, 2010).

222 The incidence of CHD, Hypertension and Diabetes is less in healthcare professionals than the

223 general population of Pakistan (Pakistan Medical Research Council. Islamabad (Pakistan),

224 1998). Injurious effects of cigarette smoking are known to all and because of all these effects

225 the number of people smoking cigarettes is reducing in developing countries but paradoxically

226 the number is on the rise in Pakistan which is reflected in $12.7 \%$ doctors smoking cigarettes as

227 compared to 3.3\% doctors in Canada and 4\% doctors in America (Frank \& Segura, 2009).

228 Almost half of the healthcare professionals sleep $<7$ hours which may be due to job stress,

229 long working hours etc. Healthcare professionals have to work, on average, $>50$ hours/week

230 to compensate for the scarcity of resources e.g. man power etc. (Pakistan Medical and Dental

231 Council (PMDC) and in turn take a heavy toll on their own health and family life. Lack of

232 sufficient sleep and long working hours lead to increased mistakes and hospital mortality

233 which is especially a cause of concern in a country which has very limited number of

234 healthcare professionals to share the heavy patient load (Weinger \& Ancoli-Israel, 2002; 
235 Editorial, 2009). Doctors work almost 17 hours/week more than the European Work Time

236 Directive (EWTD) (The Europen Parliament, 2003) which limits the working of doctors to 40-48

237 hours/week. No such directive is present at the moment in Pakistan which in a way opens the

238 flood gates for doctors and other healthcare professionals to suffer from the ill effects of long

239 working hours e.g. burnout, drowsiness during driving, mistakes etc. This also affects their

240 family life with only $34.5 \%$ healthcare professionals being able to spend time with their

241 families as much as they like to. Junior doctors, when compared with senior doctors had lower

242 mental wellbeing scores, lower breakfast frequency, greater fast-food frequency, longer

243 working hours, lower exercise and poor job satisfaction (Table 2). Occupational stress is part

244 of any job but it is of paramount importance in professions dealing with lives (National

245 Institute of Occupational Safety and Health, 1988). Healthcare professionals in Jamaica

246 reported work related stress (occupational stress) to be 4 times more than non-work related

247 stress (Lindo et al., 2006). 70\% of Pakistani healthcare professionals said they perceive

248 themselves to be under occupational stress which works as a double edged sword damaging

249 the wellbeing of healthcare professionals at one end and causing poor patient care at the

250 other. Despite all the difficulties in healthcare profession only $28 \%$ healthcare professionals

251 would change their profession, if given a chance, which shows sheer dedication and resilience

252 towards patient welfare and stressors respectively.

253

254 Limitations and Recommendations for Further

255 Research: 
- The proportion of dentists was small because of severe shortage of such professionals in the country e.g. there is only 1 dentist for a population of 12,000(Pakistan Medical and Dental Council (PMDC)) as opposed to 1 dentist for a population of 1600 in

American Heart Association. 2013. Physical activity improves quality of life. 
Clarke A, Friede T, Putz R, Ashdown J, Martin S, Blake A, Adi Y, Parkinson J, Flynn P, Platt S, Stewart-Brown S. 2011. Warwick-Edinburgh Mental Well-being Scale (WEMWBS): validated for teenage school students in England and Scotland. A mixed methods assessment. BMC public health 11:487.

Deacon L, Carlin H, Spalding J, Giles S, Stansfield J, Hughes S, Perkins C, Bellis MA. 2009. North West Mental Wellbeing Survey. :7.

Editorial. 2009. Doctors get ill too. Lancet 374:1653.

Foley D, Ancoli-Israel S, Britz P, Walsh J. 2004. Sleep disturbances and chronic disease in older adults: results of the 2003 National Sleep Foundation Sleep in America Survey. Journal of psychosomatic research 56:497-502.

Frank E. 2004. PHysician health and patient care. JAMA 291:637.

Frank E, Breyan J, Elon L. 2000. Physician disclosure of healthy personal behaviors improves credibility and ability to motivate. Archives of family medicine 9:287-90.

Frank E, Segura C. 2009. Health practices of Canadian physicians. Canadian Family Physician 55:810-811.

Gallup Pakistan. 2011. 30 YEARS OF POLLING ON EATING HABITS OF PAKISTANIS (1980-2010).

Gambera PJ, Schneeman BO, Davis P a. 1995. Use of the Food Guide Pyramid and US Dietary Guidelines to improve dietary intake and reduce cardiovascular risk in active-duty Air Force members. Journal of the American Dietetic Association 95:1268-73.

General Dental Council U. Facts and Figures.

Gupta K, Fan L. 2009. Doctors: fighting fit or couch potatoes? British Journal of Sports Medicine $43: 153-154$.

Haskell WL, Lee I-M, Pate RR, Powell KE, Blair SN, Franklin BA, Macera C a, Heath GW, Thompson PD, Bauman A. 2007. Physical activity and public health: updated recommendation for adults from the American College of Sports Medicine and the American Heart Association. Circulation 116:1081-93.

Huppert FA. 2009. Psychological Well-being: Evidence Regarding its Causes and Consequences. Applied Psychology: Health and Well-Being 1:137-164.

Kazmi R, Amjad S, Khan D. 2008. Occupational stress and its effect on job performance. A case study of medical house officers of district Abbottabad. J Ayub Med Coll Abbottabad 20:135-139. 
Lindo JLM, McCaw-Binns a, LaGrenade J, Jackson M, Eldemire-Shearer D. 2006. Mental wellbeing of doctors and nurses in two hospitals in Kingston, Jamaica. The West Indian medical journal 55:153-9.

Marmot M. 2002. The Influence Of Income On Health: Views Of An Epidemiologist. Health Affairs $21: 31-46$.

National Institute of Occupational Safety and Health. 1988. Guidelines for Protecting the Health and Safety of Health Care Workers. DHHS (NIOSH) Publication No 88-119.

Oberg EB, Frank E. 2009. Physicians' health practices strongly influence patient health practices. The Journal of the Royal College of Physicians of Edinburgh 39:290-291.

Ockene IS, Miller NH. 1997. Cigarette Smoking, Cardiovascular Disease, and Stroke: A Statement for Healthcare Professionals From the American Heart Association. Circulation 96:32433247.

Peter Schattner, Sandra Davidson and Nathan Serry. 2004. Doctors' health and wellbeing: Taking up the challenge in Australia. Medical Journal of Australia 181:348-349.

Pakistan Medical and Dental Council (PMDC). Statistics on Registered Medical and Dental Professionals in Pakistan, 2014.

Pakistan Medical Research Council. Islamabad (Pakistan). 1998. National Health Survey of Pakistan 1990-94: Health profile of the people of Pakistan.

Shiwani MH. 2009. Editorial Health of Doctors: A cause of concern. JPMA. The Journal of the Pakistan Medical Association 59:194-195.

Taggart F, Friede T, Weich S, Clarke A, Johnson M, Stewart-Brown S. 2013. Cross cultural evaluation of the Warwick-Edinburgh Mental Well-being Scale (WEMWBS) --a mixed methods study. Health and quality of life outcomes 11:27.

The Europen Parliament. 2003. THE EUROPEAN WORK TIME DIRECTIVE (EWTD). Official Journal of the European Union 4:9-19.

The Henry J. Kaiser Family Foundation. Professionally Active Dentists.

The World Bank. 2014. World Population, 2013.

VanVoorhis CRW, Morgan BL. 2007. Understanding power and rules of thumb for determining sample sizes. Tutorials in Quantitative Methods for Psychology 3:43-50.

W.H.O. 1948. WHO definition of Health. 


\section{1}

63

Waqas A, Ahmad W, Haddad M, Taggart F, Muhammad Z, Bukhari MHH, Sami SA, Batool SM, Najeeb F, Hanif A, Rizvi ZA, Ejaz S. (2015) Measuring the well-being of health care professionals in the Punjab: a psychometric evaluation of the Warwick-Edinburgh Mental Well-being Scale in a Pakistani population. PeerJ PrePrints 3:e1586 https://dx.doi.org/10.7287/peerj.preprints.1084v2

Weinger MB, Ancoli-Israel S. 2002. Sleep deprivation and clinical performance. JAMA : the journal of the American Medical Association 287:955-8.

WHO EC. 2004. Public health Appropriate body-mass index for Asian populations and its implications for policy and intervention strategies. 363:157-163.

Willcock SM, Daly MG, Tennant CC, Allard BJ. 2004. Burnout and psychiatric morbidity in new medical graduates. Medical Journal of Australia 181:357-360.

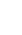

2

3

4

5

6

557

58

9

60

62 
Table $\mathbf{1}$ (on next page)

Demographics of the participants $(N=1190)$ 


\begin{tabular}{|l|l|l|}
\hline \multicolumn{3}{|l|}{ Table-1: Demographics of the participants (N=1190) } \\
\hline Healthcare Profession & Frequency & Percentage (\%) \\
\hline Doctor & 837 & 70.3 \\
\hline Nurse & 218 & 18.3 \\
\hline Dentist & 135 & 11.3 \\
\hline Gender & & \\
\hline Male & 491 & 41.3 \\
\hline Female & 699 & 58.7 \\
\hline Marital Status & & \\
\hline Married & 678 & 57.0 \\
\hline Single & 512 & 43.0 \\
\hline
\end{tabular}

2 


\section{Table 2 (on next page)}

A Comparison of Junior Doctors and Senior Doctors 


\begin{tabular}{|l|l|l|c|}
\hline \multicolumn{3}{|l|}{ Table-2. A Comparison of Junior Doctors and Senior Doctors. } \\
\hline Variable & $\begin{array}{l}\text { Junior Doctors } \\
\text { [Mean (S.D)] }\end{array}$ & $\begin{array}{l}\text { Senior Doctors } \\
\text { [Mean (S.D)] }\end{array}$ & p-value \\
\hline N=837 & 545 & 292 & - \\
\hline WEMWBS Score* & $46.76(9.63)$ & $49.52(9.22)$ & .003 \\
\hline Breakfast/Week* & $4.76(2.30)$ & $5.84(1.95)$ & .001 \\
\hline Fast-food/Week* & $2.70(2.05)$ & $1.46(1.76)$ & .001 \\
\hline Servings of Fruits/Day* & $2.54(2.35)$ & $2.21(1.72)$ & .001 \\
\hline $\begin{array}{l}\text { Servings of } \\
\text { Vegetables/Day* }\end{array}$ & $1.90(1.45)$ & $2.18(1.36)$ & .002 \\
\hline Working hours/week* & $67.33(17.13)$ & $60.58(15.43)$ & .001 \\
\hline Do exercise¥ & $18.2 \%$ & $28.4 \%$ & .002 \\
\hline $\begin{array}{l}\text { Would change their } \\
\text { profession if had the } \\
\text { option¥ }\end{array}$ & $30.3 \%$ & $24 \%$ & .02 \\
\hline *=Independent Sample t-Test, $¥=$ Pearson Chi-Square. & \\
\hline
\end{tabular}


Table 3(on next page)

Diet and Physical Health Related Characteristics of Healthcare Professionals 


\begin{tabular}{|c|c|c|c|c|c|}
\hline \multicolumn{6}{|c|}{ Table 3. Diet and Physical Health Related Characteristics of Healthcare Professionals } \\
\hline & & Doctor & Nurse & Dentist & Total \\
\hline \multirow{3}{*}{$\begin{array}{l}\text { Carbohydrates } \\
\qquad(6-11)^{a}\end{array}$} & Rec. & $58.3 \%$ & $72.0 \%$ & $56.3 \%$ & $60.6 \%$ \\
\hline & $<$ Rec. & $34.5 \%$ & $24.3 \%$ & $36.3 \%$ & $32.9 \%$ \\
\hline & $>$ Rec. & $7.2 \%$ & $3.7 \%$ & $7.4 \%$ & $6.6 \%$ \\
\hline \multirow{3}{*}{$\begin{array}{l}\text { Proteins } \\
\left(5-6 \frac{1}{2}\right)^{a}\end{array}$} & Rec. & $21.5 \%$ & $12.4 \%$ & $20.7 \%$ & $19.7 \%$ \\
\hline & $<$ Rec. & $34.6 \%$ & $70.6 \%$ & $41.5 \%$ & $42.0 \%$ \\
\hline & $>$ Rec. & $43.8 \%$ & $17.0 \%$ & $37.8 \%$ & $38.2 \%$ \\
\hline \multirow{3}{*}{$\begin{array}{l}\text { Dairy } \\
(2-3)^{a}\end{array}$} & Rec. & $8.2 \%$ & $6.4 \%$ & $7.4 \%$ & $7.8 \%$ \\
\hline & $<$ Rec. & $89.2 \%$ & $89.4 \%$ & $91.1 \%$ & $89.5 \%$ \\
\hline & > Rec. & $2.5 \%$ & $4.1 \%$ & $1.5 \%$ & $2.7 \%$ \\
\hline \multirow{3}{*}{$\begin{array}{l}\text { Fruit } \\
(4-6)^{a}\end{array}$} & Rec. & $9.0 \%$ & $4.6 \%$ & $8.1 \%$ & $8.1 \%$ \\
\hline & $<$ Rec. & $86.6 \%$ & $91.3 \%$ & $87.4 \%$ & $87.6 \%$ \\
\hline & > Rec. & $4.4 \%$ & $4.1 \%$ & $4.4 \%$ & $4.4 \%$ \\
\hline \multirow{3}{*}{$\begin{array}{l}\text { Vegetables } \\
\qquad(4-6)^{a}\end{array}$} & Rec. & $3.8 \%$ & $6.9 \%$ & $3.7 \%$ & $4.4 \%$ \\
\hline & $<$ Rec. & $94.3 \%$ & $91.3 \%$ & $93.3 \%$ & $93.6 \%$ \\
\hline & $>$ Rec. & $1.9 \%$ & $1.8 \%$ & $3.0 \%$ & $2.0 \%$ \\
\hline \multirow{3}{*}{$\begin{array}{l}\text { Fat (Saturated) } \\
\text { (Infrequently) }^{a}\end{array}$} & Infrequently & $57.8 \%$ & $68.3 \%$ & $37.8 \%$ & $57.5 \%$ \\
\hline & Often & $34.3 \%$ & $26.6 \%$ & $43.7 \%$ & $33.9 \%$ \\
\hline & Frequently & $7.9 \%$ & $5.0 \%$ & $18.5 \%$ & $8.6 \%$ \\
\hline \multirow{3}{*}{$\begin{array}{l}\text { Fat (Unsaturated) } \\
\text { (Infrequently) }^{a}\end{array}$} & Infrequently & $68.5 \%$ & $70.6 \%$ & $42.2 \%$ & $65.9 \%$ \\
\hline & Often & $26.5 \%$ & $26.1 \%$ & $43.0 \%$ & $28.3 \%$ \\
\hline & Frequently & $5.0 \%$ & $3.2 \%$ & $14.8 \%$ & $5.8 \%$ \\
\hline \multirow{3}{*}{$\begin{array}{c}\text { Sugars } \\
(\text { Infrequently) }\end{array}$} & Infrequently & $29.0 \%$ & $39.9 \%$ & $32.6 \%$ & $31.4 \%$ \\
\hline & Often & $40.9 \%$ & $42.7 \%$ & $40.0 \%$ & $41.1 \%$ \\
\hline & Frequently & $30.1 \%$ & $17.4 \%$ & $27.4 \%$ & $27.5 \%$ \\
\hline $\begin{array}{c}\text { Water glass }(250 \mathrm{ml}) / \\
\text { Day }\end{array}$ & $1<6$ & $35.2 \%$ & $20.2 \%$ & $53.3 \%$ & $34.5 \%$ \\
\hline
\end{tabular}




\begin{tabular}{|c|c|c|c|c|c|}
\hline & $6-8$ & $36.2 \%$ & $43.1 \%$ & $26.7 \%$ & $36.4 \%$ \\
\hline & $>8$ & $28.6 \%$ & $36.7 \%$ & $20.0 \%$ & $29.1 \%$ \\
\hline \multirow{3}{*}{$\begin{array}{c}\text { Breakfast } \\
\text { frequency/Week }\end{array}$} & Daily & $47.9 \%$ & $55.0 \%$ & $51.1 \%$ & $49.6 \%$ \\
\hline & $<7$ & $47.2 \%$ & $41.3 \%$ & $44.4 \%$ & $45.8 \%$ \\
\hline & None & $4.9 \%$ & $3.7 \%$ & $4.4 \%$ & $4.6 \%$ \\
\hline \multirow{4}{*}{$\begin{array}{c}\text { Fast Food Frequency/ } \\
\text { Week }\end{array}$} & $>7$ & $1.7 \%$ & $0.9 \%$ & $0.0 \%$ & $1.3 \%$ \\
\hline & $5-7$ & $10.5 \%$ & $5.5 \%$ & $14.8 \%$ & $10.1 \%$ \\
\hline & $<5$ & $73.6 \%$ & $62.4 \%$ & $77.0 \%$ & $71.9 \%$ \\
\hline & None & $14.2 \%$ & $31.2 \%$ & $8.1 \%$ & $16.6 \%$ \\
\hline \multirow{4}{*}{$\begin{array}{c}\text { BMI }^{\mathrm{b}} \\
\left(\mathrm{kg} / \mathrm{m}^{2}\right)\end{array}$} & $<18.5$ & $7.4 \%$ & $6.9 \%$ & $7.4 \%$ & $7.3 \%$ \\
\hline & $18.5 \leq 24.9$ & $61.2 \%$ & $45.9 \%$ & $60.0 \%$ & $58.2 \%$ \\
\hline & $25 \leq 30$ & $26.8 \%$ & $39.4 \%$ & $30.4 \%$ & $29.5 \%$ \\
\hline & $>30$ & $4.7 \%$ & $7.8 \%$ & $2.2 \%$ & $5.0 \%$ \\
\hline \multirow[t]{3}{*}{ Exercise $^{c}$} & $\geq$ Rec. & $11.4 \%$ & $7.8 \%$ & $27.4 \%$ & $12.5 \%$ \\
\hline & $<$ Rec. & $10.4 \%$ & $15.1 \%$ & $10.4 \%$ & $11.3 \%$ \\
\hline & None & $78.3 \%$ & $77.1 \%$ & $62.2 \%$ & $76.2 \%$ \\
\hline \multirow[t]{5}{*}{ Chronic Diseases } & Coronary Heart Disease & $1.9 \%$ & $3.2 \%$ & $0.7 \%$ & $2.0 \%$ \\
\hline & Hypertension & $7.3 \%$ & $8.3 \%$ & $5.2 \%$ & $7.2 \%$ \\
\hline & Diabetes Mellitus & $4.2 \%$ & $6.0 \%$ & $3.0 \%$ & $4.4 \%$ \\
\hline & Visual Defects & $27.0 \%$ & $10.1 \%$ & $15.6 \%$ & $22.6 \%$ \\
\hline & Back Problems & $9.1 \%$ & $13.3 \%$ & $8.1 \%$ & $9.7 \%$ \\
\hline \multicolumn{6}{|c|}{$\begin{array}{l}\text { a Servings/Day according to DIETARY GUIDELINES FOR AMERICANS, } 2010 \text { (between 1800-2600 Calories) } \\
\text { b Body-mass index (BMI) cut-off points by WHO. } \\
\text { c Exercise guidelines by American Heart Association (150mins/week of moderate activity or 75mins/week of } \\
\text { vigorous activity or a combination of both). }\end{array}$} \\
\hline
\end{tabular}




\section{Table 4(on next page)}

Perception of Occupational Stressors by Healthcare Professionals. 


\begin{tabular}{|l|l|l|l|l|}
\hline \multicolumn{5}{|l|}{ Table 4. Perception of Occupational Stressors by Healthcare Professionals. } \\
\hline Occupational Stressors & Doctor & Nurse & Dentist & Total \\
\hline Long Working Hours & $59.9 \%$ & $34.9 \%$ & $49.6 \%$ & $54.1 \%$ \\
\hline Patient Overload & $62.8 \%$ & $42.2 \%$ & $49.6 \%$ & $57.6 \%$ \\
\hline Uncertain Future & $56.9 \%$ & $28.0 \%$ & $49.6 \%$ & $50.8 \%$ \\
\hline Insufficient Opportunities to prosper & $56.3 \%$ & $26.6 \%$ & $47.4 \%$ & $49.8 \%$ \\
\hline $\begin{array}{l}\text { Illegitimate political, administrative etc. } \\
\text { pressure }\end{array}$ & $50.7 \%$ & $22.0 \%$ & $40.0 \%$ & $44.2 \%$ \\
\hline
\end{tabular}




\section{Table 5 (on next page)}

Multiple regression analysis for WEMWBS scores in Healthcare Professionals $(n=1190)$ 


\begin{tabular}{|c|c|c|c|c|c|c|}
\hline \multirow{3}{*}{ Variable } & \multicolumn{4}{|c|}{ Table-5: Multiple regression analysis for WEMWBS scores in Healthcare Professionals $(n=1190)$} & \multirow{2}{*}{\multicolumn{2}{|c|}{$95 \% \mathrm{CI}$ for $\mathrm{B}$}} \\
\hline & \multicolumn{2}{|c|}{$\begin{array}{l}\text { Under standardized } \\
\text { coefficients }\end{array}$} & \multirow{2}{*}{\begin{tabular}{|c|}
$\begin{array}{l}\text { Standardized } \\
\text { coefficients }\end{array}$ \\
Beta \\
\end{tabular}} & & & \\
\hline & $\mathrm{B}$ & Std. error B & & & Lower bound & Upper bound \\
\hline (Constant) & 52.150 & 3.360 & & .000 & 45.558 & 58.742 \\
\hline $\begin{array}{l}\text { Most of the meals you eat are } \\
\text { restaurant made? }\end{array}$ & -1.150 & .627 & -.049 & .067 & -2.379 & .080 \\
\hline $\begin{array}{l}\text { How many cups of tea you take in a } \\
\text { day? }\end{array}$ & -.377 & .137 & -.072 & .006 & -.645 & -.109 \\
\hline $\begin{array}{l}\text { How many cups of coffee you take } \\
\text { in a day? }\end{array}$ & -.563 & .271 & -.054 & .038 & -1.095 & -.031 \\
\hline $\begin{array}{l}\text { Do you take any supplements (Iron } \\
\text { or Vit.D etc)? }\end{array}$ & 1.336 & .638 & .054 & .037 & .084 & 2.588 \\
\hline Hypertension & 2.059 & .958 & .056 & .032 & .180 & 3.939 \\
\hline Back problems & -2.762 & .829 & -.086 & .001 & -4.389 & -1.135 \\
\hline $\begin{array}{l}\text { Do you think you are treated in a } \\
\text { way you deserve to be treated in the } \\
\text { society? }\end{array}$ & -2.885 & .543 & -.146 & .000 & -3.951 & -1.819 \\
\hline $\begin{array}{l}\text { If you could go back in time, would } \\
\text { you choose a different profession? }\end{array}$ & 3.136 & .552 & .148 & .000 & 2.053 & 4.220 \\
\hline $\begin{array}{l}\text { Do you feel under occupational } \\
\text { stress? }\end{array}$ & -4.081 & .743 & -.196 & .000 & -5.539 & -2.622 \\
\hline Uncertain Future & 2.639 & .816 & .138 & .001 & 1.038 & 4.239 \\
\hline $\begin{array}{l}\text { Illegitimate political, administrative } \\
\text { pressure }\end{array}$ & -2.009 & .756 & -.105 & .008 & -3.492 & -.526 \\
\hline Unsaturated fatty acid intake & 1.139 & .526 & .057 & .031 & .107 & 2.171 \\
\hline Exercise (recommended vs none) & -2.500 & .752 & -.087 & .001 & -3.975 & -1.025 \\
\hline Exercise ( $<$ recommended vs none) & -1.684 & .785 & -.056 & .032 & -3.225 & -.143 \\
\hline Grain intake & 1.331 & .529 & .066 & .012 & .293 & 2.368 \\
\hline Protein intake & 1.086 & .516 & .056 & .036 & .073 & 2.099 \\
\hline Fruit intake & 1.681 & .761 & .058 & .027 & .189 & 3.174 \\
\hline Body mass index & 2.191 & .944 & .060 & .020 & .339 & 4.043 \\
\hline Working hours & 3.490 & .745 & .128 & .000 & 2.029 & 4.951 \\
\hline Breakfast intake & 1.215 & .506 & .064 & .017 & .222 & 2.209 \\
\hline Income & -2.120 & .846 & -.068 & .012 & -3.781 & -.460 \\
\hline
\end{tabular}

